\title{
ANALISIS MOTIVASI DAN LINGKUNGAN KERJA TERHADAP KINERJA PEGAWAI PADA BADAN PENANGGULANGAN BENCANA DAERAH PROVINSI SUMATERA UTARA
}

\author{
Dinda Alya Novia, Awaludin \\ Fakultas Ekonomi dan Bisnis, Universitas Tjut Nyak Dhien, Program Studi Manajemen \\ Email : arcanakaili@gmail.com
}

\begin{abstract}
This study aims to analyze the effect of motivation and work environment on employee performance at the regional disaster management agency in the province of North Sumatra. Quantitative descriptive is the method used with the total population in this study, namely the number of employees of BPBD of North Sumatra in the field of prevention and preparedness as many as 35 people. Data was processed using SPSS and analyzed using data quality test, multiple linear regression test, and coefficient of determination test. The results of the study show that motivation and work environment have a significant influence on the employee performance of North Sumatra Province BPBD, either partially or simultaneously.
\end{abstract}

Keywords: motivation, work environment, employee performance

\begin{abstract}
Abstrak
Penelitian ini mempunyai tujuan menganalissi pengaruh motivasi dan lingkungan kerja berkenaan dengan kinerja pegawai pada BPBD provinsi sumatera utara. Deskriptif kuantitatif merupakan metode yang digunakan dengan jumlah populasi dalam penelitian ini, yaitu jumlah pegawai bpbd provinsi sumatera utara padabidang pencegahan dan kesiapsiagaan sebanyak 35 orang. dan sampel diambil seluruhnya yaitu 35 orang. data diolah menggunakan spss dan dianalisis menggunakan uji kualitas data, uji regresi linier berganda, dan uji koefisien determinasi. hasil penelitian menunjukkan motivasi dan lingkungan kerja mempunyai pengaruh signifikan terhadap kinerja pegawai BPBD Provinsi Sumatera Utara baik secara parsial maupun simultan
\end{abstract}

Kata kunci : Motivasi, lingkungan kerja, kinerja pegawai

\section{Pendahuluan}

Sumber daya manusia yang dikelola oleh badan pemerintah dituntut agar dapat dioptimalkan dengan sebaik mungkin. Hal ini tidak terlepas dari faktor pegawai yang memiliki prestasi baik agar tujuan instansi pemerintah tercapai. Pegawai merupakan substansi penting dari suatu badan yang bertanggung jawab sebagai ahli pikir, penyusun strategi, dan pengatur kegiatan.
Organisasi memiliki fungsi penting dalam membangun motivasi dan meningkatkan kinerja para pegawai sehingga terlahirnya pegawai yang bersikap profesional dalam menyelesaikan tanggung jawabnya masing-masing. Tentunya, hal ini sangat berdampak postif untuk perkembangan organisasi kedepannya serta terwujudnya tujuan organisasi. 
Vol. 2 No. 2 Bulan Oktober 2021 - Maret 2022

Lingkungan kerja merupakan kondisi material maupun psikologis yang tersedia pada sebuah instansi. Ada 2 jenis lingkungan kerja, yaitu lingkungan fisik dan non-fisik. Lingkungan fisik mencakup susunan ruangan kantor yang bersih dan nyaman, sirkulasi udara yang baik serta pencahayaan ruang yang memadai sedangkan lingkungan non-fisik meliputi hubungan sesama pegawai maupun pimpinan, kesejahteraan pegawai, situasi para pegawai saat bekerja, serta tempat beribadah. Kinerja pegawai dapat meningkat secara optimal bersamaan dengan terciptanya lingkungan kerja yang baik.

Pengoptimalan peningkatan kerja dan kemampuan mendayagunakan potensi Sumber Daya Manusia yang dimiliki oleh pegawai sangat dibutuhkan untuk membangun kinerja kerja yang tinggi agar tujuan organisasi dapat tercipta.

Unsur pendukung tugas Gubernur Sumatera Utara dalam pengelolaan pemerintah daerah di bidang penanggulangan bencana adalah BPBD yang dipimpin oleh Kepala Badan yang berada di bawah dan bertanggung-jawab kepadaGubernur (Pergub Nomor 31 Tahun 2019 Pasal 2 Ayat (3)). Sumber daya manusia yang profesional diperlukan untuk menjalankan sistem operasional kegiatan agar program kerja dapat terealisasi dengan baik. Hal ini berpengaruh terhadap kelancaran kinerja organisasi/instansi itu sendiri,oleh sebab itu adanya motivasi dan lingkungan kerja yang baik sangat berpengaruh terhadap fungsi pengarahan yang terdapat di dalam instansi sebagai pendorong kinerja para pegawai.

BPBD bertanggung jawab untuk mempersiapkan tenaga yang berkualitas agar mampu menanggulangi bencana dengan baik karena banyaknya bencana alam di Indonesia khususnya Provinsi Sumatera Utara dimana pihak instansi yang terkait harus membenahi diri masingmasing untuk lebih baik lagi.

Berdasarkan hasil survey data tahun 2021, BPBD Provinsi Sumatera Utara memiliki berbagai bidang yang terbagi berlandaskan pada tugas pokok dan fungsi masingmasing, seperti Bidang Pencegahan dan Kesiapsiagaan. Bidang Pencegahan dan Kesiapsiagaan merupakan salah satu bagian yang sangat penting pada BPBD Provinsi Sumatera Utara karena terdapat pada Peraturan Gubernur Nomor 31 Tahun 2019 berisi tentang Tugas Fungsi, Uraian Tugas dan Tata Kerja BPBD Provinsi Sumatera Utara, Pencegahan dan Kesiapsiagaan bencana pada pra bencana. 
Berikut di bawah ini adalah tabel yang memaparkan tentang status kepegawaian yang ada di BPBD Sumatera Utara. Bidang pencegahan dan kesiapsiagaan memiliki daftar kapasitas pegawai pada tabel di bawah ini:

Tabel 1. Daftar Kapasitas pegawai Bidang Pencegahan dan Kesiapsiagaan

\begin{tabular}{|l|l|l|}
\hline No. & Status Kapasitas Kepegawaian & Jumlah Pegawai \\
\hline 1 & Kepala Bidang Pencegahan dan Kesiapsiagaan & 1 Orang \\
\hline 2 & Kasubbid Pengurangan Risiko Bencana & 1 Orang \\
\hline 3 & Kasubbid Kesiapsiagaan & 1 Orang \\
\hline 4 & Kasubbid Pemberdayaan Masyarakat & 1 Orang \\
\hline 5 & Analis Mitigasi Bencana & 2 Orang \\
\hline 6 & Penyuluh Bencana & 3 Orang \\
\hline 7 & Pelatih Satuan Pelindung Masyarakat & 1 Orang \\
\hline 8 & Pranata Teknologi Informasi Komputer & 1 Orang \\
\hline 9 & SATGAS Penanggulangan Bencana & 24 Orang \\
\hline Total Pegawai & 35 Orang \\
\hline
\end{tabular}

Sumber: BPBD Provinsi Sumatera Utara (2021)

Peran BPBD Provinsi Sumatera

Utara pada Bidang Pencegahan dan Kesiapsiagaan berfungsi sebagai wadah untuk memberikan pemahaman, sosialisasi serta pelatihan kepada masyarakat untuk menghadapi bencana yang bisa kapan saja terjadi. Sumber daya manusia yang disediakan oleh BPBD Provinsi Sumatera Utara dituntut menyerahkan yang terbaik, cekatan, taat serta professional supaya kinerja kerja mereka semakin meningkat.

Permasalahan pada BPBD Provinsi Sumatera Utara khususnya pada bidang pencegahan dan kesiapsiagaan yaitu terdapat kinerja pegawai yang tidak memenuhi syarat dilihat dari hasil kinerja pegawai yang tidak optimal dan tidak disiplin serta masih ditemukan pegawai yang bermalas-malasan dalam melaksanakan kinerjanya. Selain itu permasalahan lingkungan kerja pada instansi ini mencakup permasalahan lingkungan kerja non-fisik seperti hubungan kerja sesama pegawai masih sangat kurang harmonis sedangkan permasalahan lingkungan kerja fisik yakni pergantian udara yang tidak baik dikarenakan kurangnya kesadaran pegawai yang merokok didalam ruangan yang menyebabkan pendingin ruangan tidak bekerja secara optimal untuk menyejukkan ruangan guna membuat pegawai lainnya menikmati kenyamanan untuk mengerjakan tanggung jawabnya. Hal ini sangat berpengaruh dalam keberhasilan instansi. selain itu, kurang tertatanya ruangan kerja pegawai yang menyebabkan banyak barang-barang tidak tersusun dan menyebabkan kurangnya ruang gerak pegawai didalam ruangan. Dari penjabaran di atas tujuan penulis untuk mengkaji pengaruh motivasi di lingkungan kerja terhadap kinerja para pegawai di BPBD Provinsi Sumatera Utara. 


\section{Vol. 2 No. 2 Bulan Oktober 2021 - Maret 2022}

\section{Tinjauan Pustaka}

\section{Kinerja}

Kinerja merupakan penilaian hasil kerja berupa kombinasi dari adanya usaha, kemampuan, dan kesempatan. Proses penilaian kinerja oleh instansi diawali dengan mengawasi pelaksanaan individu dan dalam kurun waktu tertentu, kontribusi pegawai baru bisa dinilai. Menurut Simamora (2019) pekerjaan pegawai yang dibentuk dari tingkatan pencapaian tugas berpengaruh terhadap kinerja (performance) dan feedback dari penilaian kinerja membantu pegawai untuk mengetahui kinerja mereka jika dibandingkan dengan standar institusi.

\section{Motivasi}

Wibowo M (2012) menyatakan bahwa dorongan yang terlihat di dalam diri pegawai untuk bekerja semaksimal mungkin agar target instansi tercapai merupakan bentuk dari perwujudan motivasi. Menurut pandangan Siagian (2012) movere yang bersumber dari bahasa latin yang berarti dorongan/penggerak. Motivasi merupakan dorongan yang memberikan dampak kepada individu agar bersedia mengerahkan kemampuan dan waktunya untuk melaksanakan kewajiban yang telah ditetapkan demi tercapainya tujuan suatu instansi.

\section{Lingkungan kerja}

Sedarmayanti (2011) mengemu

kakan bahwa keseluruhan alat dan bahan yang ditemui, lingkungan sekitar, metode kerja, dan pengaturan kerja baik secara individu maupun kelompok merupakan pengertian dari lingkungan kerja. Berbeda hal dengan Nitisemoto (2012) yang menganggap lingkungan kerja merupakan sesuatu yang berada disekeliling yang mampu mempengaruhi para pekerja untuk menyelesaikan tanggung jawabnya.

Variabel berpengaruhnya adalah motivasi dan lingkungan kerja pegawai sedangkan variabel terpengaruhnya adalah kinerja pegawai. Berikut adalah gambar 1 yang menyajikan kerangka konseptual:

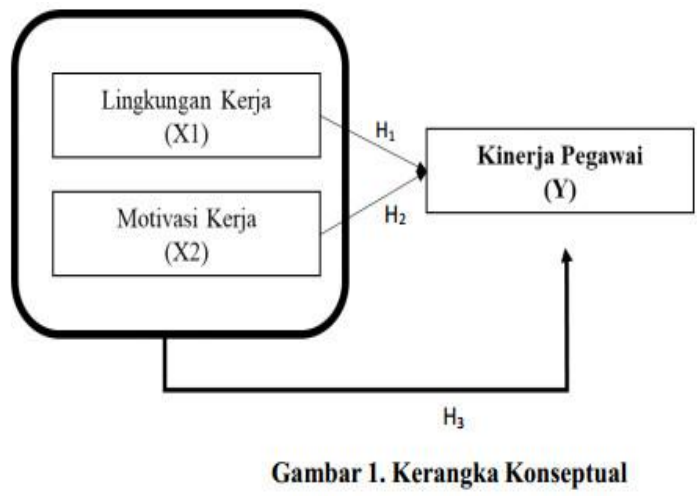

H1: Pengaruh lingkungan kerja terhadap Kinerja pegawai

H2: Pengaruh Motivasi kerja terhadap kinerja pegawai

H3: Pengaruh Lingkungan kerja dan Motivasi Kerja Terhadap Kinerja pegawai 


\section{Metode Penelitian}

Metode penelitian menggunakan deskriptif kuantitatif. Dengan jumlah populasi dalam penelitian ini adalah jumlah pegawai BPBD Provinsi Sumatera Utara padaBidang Pencegahan dan Kesiapsiagaan sebanyak 35 Orang. Dan sampel diambil seluruhnya yaitu 35 orang. data diolah menggunakan SPSS dan dianalisis menggunakan uji kualitas data, uji regresi linier berganda, dan uji koefisien determinasi.

\section{Hasil Penelitian dan Pembahasan}

\subsection{Hasil Penelitian}

Tabel 2. Tes Validitas Motivasi

\begin{tabular}{|l|c|c|c|}
\hline Variabel & rhitung & rtabel & Keterangan \\
\hline $\mathrm{X} 11$ & .434 & .329 & Valid \\
\hline $\mathrm{X} 12$ & .390 & .329 & Valid \\
\hline $\mathrm{X} 13$ & .569 & .329 & Valid \\
\hline $\mathrm{X} 14$ & .654 & .329 & Valid \\
\hline $\mathrm{X} 15$ & .822 & .329 & Valid \\
\hline $\mathrm{X} 16$ & .621 & .329 & Valid \\
\hline
\end{tabular}

Sumber: Diolah Peneliti (2021)

\section{Tabel 3. Tes Validitas Lingkungan Kerja}

\begin{tabular}{|l|c|c|c|}
\hline Variabel & rhitung & rtabel & Keterangan \\
\hline $\mathrm{X} 21$ & .640 & .329 & Valid \\
\hline $\mathrm{X} 22$ & .380 & .329 & Valid \\
\hline $\mathrm{X} 23$ & .767 & .329 & Valid \\
\hline $\mathrm{X} 24$ & .640 & .329 & Valid \\
\hline $\mathrm{X} 25$ & .638 & .329 & Valid \\
\hline $\mathrm{X} 26$ & .598 & .329 & Valid \\
\hline
\end{tabular}

Sumber: Diolah Peneliti (2021)
Tabel 4. Tes Validitas Kinerja Pegawai

\begin{tabular}{|l|c|c|c|}
\hline Variabel & rhitung & rtabel & Keterangan \\
\hline Y11 & .706 & .329 & Valid \\
\hline Y12 & .515 & .329 & Valid \\
\hline Y13 & .718 & .329 & Valid \\
\hline Y14 & .621 & .329 & Valid \\
\hline Y15 & .660 & .329 & Valid \\
\hline
\end{tabular}

Sumber: Diolah Peneliti (2021)

Pengolahan data yang dilakukan dari 6 butir pernyataan motivasi, lingkungan kerja dan 5 butir kinerja yang diajukan maka seluruh peryataan tentang Kepussan pelanggan terbukti valid dikarenakan nilai corrected item total correlaction secara keseluruhan bernilai $\geq$ nilai $r_{\text {tabel }}$ adalah 0,329 sehingga kuisioner dinyatakan valid dan digunakan untuk pengujian reliabilitas.

Sedangkan untuk uji reliabilitas semua variabel dinyatakan valid karena nilai Cronbach's Alpha melebihi 0,60.

Normality test dilakukan dengan menggunakan Kolmogrov-Smirnov Test tingkat signifikan $\alpha=0,05$ (5\%). Hasil Kolmogorov-Smirnov Test pada Tabel 5 berikut:

Tabel 5. Uji Normalitas One-Sample Kolmogorov-Smirnov Test

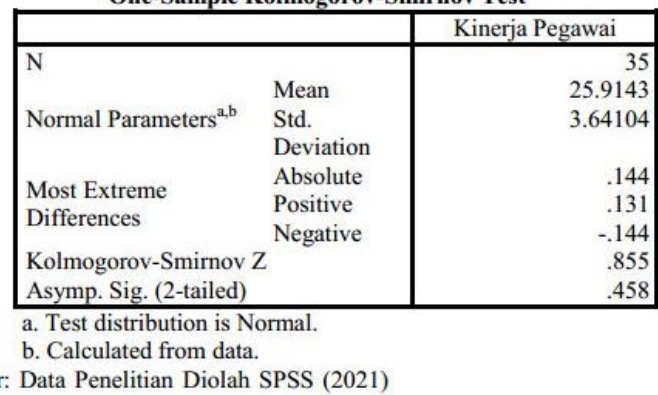


berikut:

Diketahui pada Tabel 5, data berdistribusi normal dengan nilai test statistic 0,858 sedangkan nilai Asympy.Sig (2-tailed) 0,458 di atas tingkat signifikansi 0,05 maka nilai Asympy.Sig > 0,05 $(0,458>$ $0,05)$.

Tabel 6. Uji Multikolinieritas

\begin{tabular}{|ll|r|c|}
\hline \multirow{2}{*}{ Model } & \multicolumn{2}{|c|}{ Collinearity Statistics } \\
\cline { 2 - 3 } & Tolerance & \multicolumn{1}{c|}{ VIF } \\
\hline $1 \quad$ (Constant) & & \\
& Motivasi & .114 & $\mathbf{8 . 7 5 8}$ \\
\multicolumn{2}{|l|}{ Lingkungan kerja } & $\mathbf{. 1 1 4}$ & $\mathbf{8 . 7 5 8}$ \\
\hline
\end{tabular}

a. Dependent Variable: Kinerja Pegawai Sumber : Data Penelitian Diolah SPSS (2021)

Berdasarkan data pada Tabel 16, menunjukkan bahwa Tolerance Value variabel Motivasi dan Lingkungan Kerja masing-masing sebesar $(0,114>0,10)$ sedangkan nilai VIF dari variabel Motivasi dan Lingkungan Kerja masing-masing sebesar $(8,758<10,00)$ data ini menunjukkan bahwa kuisioner penelitian tidak terjadi multikolinieritas atau dikatakan kolinieritas.

\section{Uji t (Partial Test)}

T-test (partial test) diberikan untuk mengamati pengaruh signifikan dari variabel independen (X) Motivasi dan Lingkungan Kerja terhadap variabel terikat (Y) Kinerja Pegawai secara individual pada BPBD Provinsi Sumatera Utara, terlihat pada tabel
Tabel 7. Uji t

\begin{tabular}{|c|c|c|c|c|c|c|c|}
\hline & & Coeffici & ients ${ }^{\mathrm{a}}$ & & & & \\
\hline \multirow[b]{2}{*}{ Model } & \multicolumn{2}{|c|}{$\begin{array}{c}\text { Unstandardized } \\
\text { Coefficients }\end{array}$} & \multirow{2}{*}{$\begin{array}{c}\begin{array}{c}\text { Standardized } \\
\text { Coefficients }\end{array} \\
\text { Beta }\end{array}$} & \multirow[b]{2}{*}{$t$} & \multirow[b]{2}{*}{ Sig. } & \multicolumn{2}{|c|}{$\begin{array}{c}\text { Collinearity } \\
\text { Statistics }\end{array}$} \\
\hline & B & $\begin{array}{c}\text { Std. } \\
\text { Error }\end{array}$ & & & & Toleranc & VIF \\
\hline 1 (Constant) & .241 & 1.072 & & .225 & .823 & & \\
\hline Motivasi & .383 & .124 & .351 & 3.094 & .004 & .114 & 8.758 \\
\hline $\begin{array}{l}\text { Lingkungan } \\
\text { kerja }\end{array}$ & .651 & .115 & .639 & 5.640 & .000 & .114 & 8.758 \\
\hline
\end{tabular}

Berdasarkan data pada Tabel 18, coefficients value dari tiap-tiap variabel secara parsial, yakni:

\section{Pengaruh Motivasi ( $\left.\mathbf{X}_{1}\right)$ terhadap Kinerja Pegawai (Y)}

Hasil nilai thitung variabel Motivasi sebesar 3,094 dan nilai $t_{\text {tabel }}$ sebesar 2,009 (dalam Excel formula $=\operatorname{TINV}(0.05,34)$ dengan ketentuan nilai thitung lebih besar dari $t_{\text {tabel }}$ dan $\operatorname{sig}_{\text {hitung }}<\operatorname{sig}_{\text {tabel }}$ atau $(3,094>2,032)$ dan $(0,004<0,05)$. Diperoleh secara parsial variabel Motivasi $\left(\mathrm{X}_{1}\right)$ mempunyai pengaruh signifikan terhadap Kinerja Pegawai (Y) pada BPBD Provinsi Sumatera Utara.

\section{Pengaruh Lingkungan kerja $\left(\mathrm{X}_{2}\right)$ terhadap Kinerja Pegawai (Y)}

Hasil nilai thitung variabel Lingkungan kerja 5,640 dan nilai tabel sebesar 2,009 (dalam Excel formula $=\operatorname{TINV}(0.05,34)$ dengan ketentuan nilai $t_{\text {hitung }}>t_{\text {tabel }}$ dan sighitung $<$ $\operatorname{sig}_{\text {tabel }}$ atau $\left.(5,640)>2,032\right)$ dan $(0,000<$ 0,05). Diperolehvariabel Lingkungan Kerja secara parsial mempunyai pengaruh signifikan terhadap Kinerja Pegawai (Y) 
BPBD SumateraUtara Medan.

\section{Variabel Dominan Berpengaruh terhadap Kinerja Pegawai}

Hasil nilai $t_{\text {hitung }}$ variabel Motivasi adalah 3,094 dan nilai $t_{\text {hitung }}$ variabel Lingkungan Kerja sebesar 5,640 pada nilai $t_{\text {tabel }}$ sebesar 2,032 maka nilai $t_{\text {hitung }} X_{1}>t_{\text {hitung }}$ $\mathrm{X}_{2}(5,640>3,032)$. Diperoleh bahwa secara parsial variabel lingkungan kerja merupakan variabel dominan yang mempunyai pengaruh signifikan terhadap Kinerja Pegawai (Y) pada BPBD Provinsi Sumatera Utara Medan.

\section{F-test (Simultaneous Test)}

F-test (simultaneous test) diberikan untuk mengamati secara keseluruhan pengaruh signifikan terhadap variabel bebas, Motivasi $\left(\mathrm{X}_{1}\right)$ dan Lingkungan kerja $\left(\mathrm{X}_{2}\right)$ terhadap Kinerja pegawai (Y) BPBD Provinsi Sumatera Utara Medan yang menjadi variabel terikat pada Tabel 8 berikut ini:

Tabel 8 uji F

\begin{tabular}{|c|c|c|c|c|c|c|}
\hline \multicolumn{2}{|c|}{ Model } & $\begin{array}{l}\text { Sum of } \\
\text { Squares }\end{array}$ & df & Mean Square & $\mathrm{F}$ & Sig. \\
\hline \multirow[t]{3}{*}{1} & Regression & 429.594 & 2 & 214.797 & 5.013 & $.000^{\mathrm{b}}$ \\
\hline & Residual & 21.148 & 32 & .661 & & \\
\hline & Total & 450.743 & 34 & & & \\
\hline
\end{tabular}

Sumber: data diolah peneliti (2021)

Berdasarkan data pada Tabel 19, diketahui bahwa nilai $F_{\text {hitung }}$ variabel Motivasi dan Lingkungan kerja sebesar 5,013 dan nilai tabel sebesar 2,882 (dalam
Excel formula $=\mathrm{FINV}(0.05,3,34)$ dengan ketentuan nilai $F_{\text {hitung }}>\mathrm{F}_{\text {tabel }}$ dan sighitung $<$ sig $_{\text {tabel }}$ atau $(5,013>2,882)$ dan $(0,000<$ 0,05). Diperoleh bahwa Motivasi dan Lingkungan kerja mempunyai pengaruh signifikan terhadap Kinerja pegawai (Y) BPBD Provinsi Sumatera Utara secara simultan.

\section{Koefisien Determinasi $\left(\mathbf{R}^{\mathbf{2}}\right)$}

Dapat dilakukan uji koefisien determinasi $\left(\mathrm{R}^{2}\right)$ untuk memperoleh persentase atau skala kapasitas model saat merumuskan variabel terikat. Koefisien determinasi mempunyai kisaran antara $(0 \leq$ $\left.\mathrm{R}^{2} \leq 1\right)$. Semakin besar $\mathrm{R}^{2}$ maka pengaruh variabel bebas $(\mathrm{X})$ terhadap variable terikat (Y) juga besar dimana bentuk yang difungsikan akan semakin berpengaruh dalam merumuskan kapasitas variabel bebas untuk menjelaskan variabel terikat begitu pun sebaliknya. Berikut Tabel 9:

Model Summary ${ }^{\mathrm{b}}$

\begin{tabular}{|l|r|r|r|r|}
\hline Model & \multicolumn{1}{|c|}{$R$} & R Square & \multicolumn{1}{c|}{$\begin{array}{c}\text { Adjusted R } \\
\text { Square }\end{array}$} & $\begin{array}{c}\text { Std. Error of the } \\
\text { Estimate }\end{array}$ \\
\hline 1 & $.876^{\mathrm{a}}$ & .768 & .765 & .81295 \\
\hline
\end{tabular}

a. Predictors: (Constant), Lingkungan kerja, Motivasi

b. Dependent Variable: Kinerja pegawai

Sumber: Data Penelitian Diolah SPSS (2021)

Dimana variabel bebas penelitian berkontribusi besar dalam memaparkan Kinerja Pegawai sebesar $76,80 \%$ dan $23,20 \%$ sisanya terpengaruh oleh indikator 
di luar penelitian, yakni variabel kepemimpinan, iklim dan budaya kerja serta indikator lainnya.

\subsection{Pembahasan}

Berdasarkan analisis statistik pengolahan data yang diberikan kepada tiaptiap variabel penelitian diperoleh pembahasan berikut ini, yaitu:

\section{Pengaruh Motivasi terhadap Kinerja} Pegawai BPBD Provinsi Sumatera Utara

Hal yang harus dilakukan perusahaan agar tujuannya tercapai yaitu dengan memberikan motivasi kepada para pekerja. Dalam hal ini, motivasi menjadi poin penting untuk tercapainya tujuan perusahaan karena dapat memberikan dorongan terhadap para pekerja agar optimal dalam bekerja. Kunci utama seseorang dalam melakukan sesuatu bergantung terhadap motivasi yang diberikan. Motivasi berperan sebagai penyemangat dalam mewujudkan harapan dan tujuan.

Hasil penelitian ini berbanding lurus dengan penelitian Ester Magdalena Sihombing (2020), dimana uji secara parsial mempengaruhi motivasi terhadap kinerja pegawai dan disiplin mempengaruhi kinerja pegawai BPBD Medan. Uji secara simultan membuktikan bahwa terdapat pengaruh motivasi terhadap kinerja karyawan BPBD
Medan dan memperlihatkan besarnya pengaruh motivasi, disiplin serta insentif perihal kinerja yang memiliki hasil koefisien determinasi sebesar 87,9\% sedangkan 12,1 $\%$ sisanya diuraikan oleh indikator lain.

Selanjutnya hasil penelitian SM, R Bambang (2021) menyatakan bahwa Secara parsial motivasi dan kepuasan kerja memiliki pengaruh signifikan terhadap kinerja pegawai pada Kantor BPBD Way Kanan. Pengaruh motivasi, kepuasan kerja, serta motivasi dan kepuasan kerja terhadap kinerja pegawai secara berturut adalah sebesar 49,9\%, 38,8\%, dan 52,8\%.

Dapat disimpulkan hipotesis dalam penelitian ini Motivasi mempunyai pengaruh signifikan terhadap Kinerja pegawai (Y) BPBD, dapat diterima dan terbukti kebenarannya dengan tingkat pengaruh yang signifikan.

\section{Pengaruh Lingkungan kerja terhadap Kinerja pegawai BPBD Provinsi Sumatera Utara}

Pada hakikatnya, lingkungan kerja merupakan rumah tangga kedua bagi para pekerja. Para pekerja menginginkan lingkungan kerja yang bersih dan kondusif agar tercipta hubungan kerja yang mengikat dalam lingkungan. Hal ini sangat mempengaruhi emosi para pegawai. Jika pegawai merasa nyaman di lingkungan 


\section{Vol. 2 No. 2 Bulan Oktober 2021 - Maret 2022}

kerjanya maka mereka dengan senang akan menyelesaikan tanggung jawabnya tepat waktu dan kinerja pegawai akan semakin meningkat.

Dari hasil penelitian Poni Yanita (2017) membuktikan bahwa kepemimpinan, budaya organisasi serta lingkungan kerja secara parsial membawa dampak positif dan signifikan terhadap kinerja Kantor BPBD Kabupaten Kerinci.

Kemudian hasil penelitian oleh Zulfan Yusuf (2019) memperlihatkan bahwa lingkungan kerja fisik dan komunikasi secara parsial membawa pengaruh signifikan terhadap antusiasme para pekerja pada Kantor BPBD Aceh. Hasil korelasi determinasi (R2) sebesar $87,6 \%$ perubahan di dalam variabel terikat mencakup semangat kerja yang diuraikan oleh perubahan di dalam lingkungan kerja fisik (X1) dan komunikasi (X2). 12,4\% sisanya diuraikan oleh variabel lain diluar penelitian.

Dapat disimpulkan bahwa hipotesis penelitian, yaitu Lingkungan Kerja mempunyai pengaruh signifikan terhadap Kinerja Pegawai (Y) BPBD Sumatera Utara dapat diterima dan terbukti kebenarannya dengan tingkat pengaruh yang signifikan.

\section{Pengaruh Motivasi dan Lingkungan} Kerja terhadap Kinerja pegawai B P B D Provinsi Sumatera Utara

Motivasi dapat memberi dorongan kekuatan terhadap manusia untuk meraih tujuan yang diinginkan dengan cara mendayagunakan potensi seseorang agar bekerja secara optimal dalam melaksanakan tanggung jawabnya. Kebanyakan orang berpendapat bahwa motivasi di dalam perkerjaan timbul apabila mendapatkan imbalan yang setimpal. Padahal kenyataannya walaupun sudah diberikan imbalan, pekerjaannya masih belum maksimal.

Lingkungan kerja mempunyai pengaruh terhadap motivasi kerja. Jika lingkungan kerja mendukung maka karyawan akan bersemangat dan nyaman saat melaksanakan tanggung jawabnya. Namun, jika lingkungan kerja tidak mendukung tentunya karyawan tidak akan bersemangat dalam melaksanakan tanggung jawabnya secara optimal sehingga mengakibatkan tidak tercapainya tujuan dari perusahaan.

Hasil penelitian ini berbanding lurus dengan Nurmin Arianto (2020) yang memperlihatkan bahwa terdapat pengaruh positif dari variabel motivasi $\left(\mathrm{X}_{1}\right)$ terhadap kinerja karyawan (Y) yang signifikan. Sama 


\section{Vol. 2 No. 2 Bulan Oktober 2021 - Maret 2022}

halnya dengan variabel lingkungan kerja $\left(\mathrm{X}_{2}\right)$ yang berpengaruh positif dan signifikan terhadap kinerja karyawan (Y). Secara simultan, pengaruh positif dan signifikan terdapat pada variabel motivasi $\left(\mathrm{X}_{1}\right)$ dan variabel lingkungan kerja $\left(\mathrm{X}_{2}\right)$ terhadap kinerja karyawan (Y).

Selanjutnya penelitian Enita Yuliasari (2021) memperoleh hasil bahwa variabel kepemimpinan akan berpengaruh terhadap kinerja karyawan. Dapat diverifikasi dari nilai thitung 3,167 dengan nilai $\operatorname{sig}_{t}<\alpha 0,05(0,003>0,05)$ yang memperlihatkan bahwa variabel motivasi berpengaruh terhadap kinerja karyawan. Hal ini diverifikasi dengan nilai thitung sebesar 2,891 dengan nilai sig $_{t}<\alpha 0,05(0,006<0,05)$ yang menunjukkan bahwa variabel lingkungan kerja mempunyai pengaruh terhadap kinerja karyawan. Hal ini diverifikasi dengan nilai t-hitung sebesar 3,520 dengan nilai $\operatorname{sig}_{t}<\alpha 0,05(0,001<0,05)$ yang memperlihatkan bahwa variabel disiplin kerja berpengaruh terhdap kinerja karyawan. Hal ini diverifikasi dengan nilai thitung sebesar 12,415 dengan nilai $\operatorname{sig}_{\mathrm{t}}<$ dari $\alpha 0,05(0,000>0,05)$. Nilai $R$ square sebesar $85,4 \%$ yang menunjukan adanya variabel lain yang berpengaruh terhadap kinerja pegawai.

Dapat disimpulkan bahwa Motivasi dan Lingkungan kerja secara simultan berpengaruh signifikan terhadap Kinerja Pegawai B P B D Sumatera Utara, layak diterima dan terbukti kebenarannya dengan tingkat pengaruh yang signifikan.

\section{Kesimpulan dan Saran}

\subsection{Kesimpulan}

Adanya pengaruh signifikan antara motivasi dan lingkungan kerja terhadap Kinerja Pegawai BPBD Provinsi Sumatera secara parsial ataupun simultan

\subsection{Saran}

Mengacu pada hasil penelitian maka dapat disampaikan saran untuk Pimpinan BPBD Provinsi Sumatera Utara:

1. Secara umum Motivasi pegawai pada BPBD Sumatera Utara sudah bagus tetapi masih harus ditingkatkan. Dengan memotivasi pegawai lebih serius, maka pegawai akan lebih bersemangat dan bergairah sehingga Kinerja Pegawai BPBD Sumaera Utara dapat lebih meningkat.

2. Secara umum, Lingkungan kerja Badan Penanggulangan Bencana Daerah (BPBD) Sumaera Utara sudah baik, namun diharapkan masih perlu ditingkatkan lagi. Dengan mengelola lingkungan kerja fisik dengan baik maka pegawai dapat menghasilkan kinerja 
tinggi mengingat luasnya lingkungan

kerja fisik yang harus dijangkau pegawai

Badan Penanggulangan Bencana Daerah

Sumatera Utara.

\section{DAFTAR PUSTAKA}

Enita Yuliasari (2021) Pengaruh Gaya Kepemimpinan, Motivasi, Lingkungan Kerja, Dan Disiplin Kerja Terhadap Kinerja Karyawan (Studi Kasus Pada Badan Penanggulangan Bencana Daerah Kota Batu)e - Jurnal Riset ManajemenPRODI MANAJEMEN Fakultas Ekonomi dan Bisnis Unisma website : www.fe.unisma.ac.id (email : e.jrm.feunisma@gmail.com) 175 A1 A2 A3 A4 A5 A6 A7 A8 A9 A10 A11 A12

Ester Magdalena Sihombing (2020) Pengaruh Motivasi, Disiplin, dan Insentif terhadap Kinerja Pegawai Negeri Sipil BPBD Kota Medan Civitas: Jurnal Studi Manajemen Vol. 2, No. 1, p. 14-19, Januari 2020, eISSN 2685-631X http://journals.synthesispublication.o rg/index.php/civitas.

Nitisemito, Alex S. 2012, Manajemen

Personalia. Cetakan ke 9. Edisi ke

4. Ghalia Indonesia, Jakarta.

Nurmin Arianto (2020) Pengaruh Motivasi dan Lingkungan Kerja Terhadap Kinerja pegawai BPBD Provinsi Riau Jurnal Ilmiah, Manajemen Sumber Daya Manusia JENIUS Pengaruh Motivasi dan Lingkungan Kerja Terhadap Kinerja Karyawan

Poni Yanita (2017) Pengaruh

Kepemimpinan, Budaya Organisasi,
Lingkungan Kerja Terhadap Kinerja

Pada Pegawai Kantor Badan

Penanggulangan Bencana Daerah

Kabupaten Kerinci. Jurnal Benefita 2(2) Juli 2017 (150-156)

Sedarmayanti. 2011. Manajemen Sumber Daya Manusia. Reformasi Birokrasi dan Manajemen Pegawai Negeri Sipil, Cetakan Kelima, PT Refika Aditama, Bandung.

Simamora, 2019, Manajemen Sumber Daya Manusia, STIE. YKPN, Yogyakarta.

SM, R Bambang (2021). Pengaruh Motivasi dan Kepuasan Kerja Terhadap Kinerja Pegawai Pada Kantor Badan Penanggulangan Bencana Daerah Kabupaten Way Kanan. Jurnal Ilmiah GEMA EKONOMI, [S.1.], v. 11, n. 2 Agustus, p. 1860-1868, aug. 2021. ISSN 2775-636X.

Wibowo.2012.Manajemen Kinerja: Edisis tiga. Jakarta: rajawali press

Zulfan Yusuf (2019) Pengaruh Lingkungan Kerja Fisik dan Komunikasi Terhadap Semangat Kerja Pegawai Pada Kantor Bandan Penanggulangan Bencana Daerah (BPBD) Aceh. Jurnal Ekonomi Manajemen dan Akuntansi Vol. 5 No. 1 Th 2019 eISSN 2579-5635 p-ISSN 2460-5891. 